prosecution should cease to have effect when fresh proceedings are taken, e.g. On arrival of the accused in court. The recently adopted policy on reprosecution, together with legislative change, would ensure that the effect of a finding of unfitness to plead would not necessarily be permanent. Psychiatric disorders run a fluctuating course and the capacity of a person to stand trial may similarly alter over time. Court procedure and criminal legislation should reflect these clinical facts.

\section{Acknowledgement}

The co-operation of the Crown Office in the preparation of this paper is gratefully acknowledged but the opinions expressed are entirely those of the authors.

\section{References}

CHiswick, D. (1978) Insanity in bar of trial: a state hospital study. British Journal of Psychiatry, 132, 598-601.

- (1990) Criminal responsibility in Scotland. In Principles and Practice of Forensic Psychiatry (eds R. Bluglass \& P. Bowden). Edinburgh: Churchill Livingstone.

Emmins, C. (1986) Unfitness to plead: thoughts prompted by Glenn Pearson's case. Criminal Law Review, 604-618.

Home Office and Department of Health and Social SECURITY (1975) Report of the Committee on Mentally Abnormal Offenders. Cmnd 6244. London: HMSO.

Normand, A. C. (1984) Unfitness for trial in Scotland: proposed adjudication of the facts and the right to reprosecute. International Journal of Law and Psychiatry, $7,415-435$.

Scottish Home and Health Department and Crown OfFICE (1975) Criminal Procedure in Scotland (second report). Cmnd 6218. Edinburgh: HMSO.

\title{
Trends in recruitment of new long-stay male schizophrenics
}

\author{
Norman A. Todd, Consultant Psychiatrist; ERnest H. Bennie, Consultant Psychiatrist; \\ A. F. COOPer, Consultant Psychiatrist; JosePh P. MCKane, Consultant Psychiatrist; \\ and Linda J. WATt, Consultant Psychiatrist, Leverndale Hospital, Glasgow G53 7TU
}

In 1973 a survey was carried out of male schizophrenic patients who had become long-stay residents in Leverndale Hospital, Glasgow, 'long-stay' being defined as having been continuously in hospital for more than three years (Todd et al, 1976). The patients were recruited from a four year cohort of admissions in the years 1967 to 1970 inclusive. In the following years there have been many changes in the provision of facilities and in clinical practice. In some countries, such as Italy, the USA and England, there has been a strong drive to reduce long-stay populations along with the closure of some mental hospitals. In Scotland the process has been much more gradual, possibly reflecting the differences in preexisting provisions and patterns of care.

Since 1973 there have, nevertheless, been major developments in Glasgow. The community nursing service, group homes, day hospitals and out-patient clinics at health centres have all added to the network of community support, although hostel accommodation has not yet played a significant part. Pro- grammes of rehabilitation have been developed in the hospital and linked to the other facilities. The main treatment advance during these years has been the increasing use of depot neuroleptic therapy. In view of these changes, a further survey was carried out in 1987.

Male patients were identified on 12 April 1987 from an annual hospital census as having been admitted with a diagnosis of schizophrenia (ICD-9) for the four years April 1980 to April 1984, and not discharged. They were assessed in respect of age, duration of illness, number of previous admissions, marital status, place of origin, occupation in hospital, and any special characteristics.

It has to be explained that during the period between 1973 and 1987 there were changes in the catchment area of Leverndale Hospital which is now shared with a neighbouring district general hospital psychiatric unit. This unit, however, has always been able to refer patients to Leverndale Hospital if longterm care is required. The inner-city population has 
fallen and the catchment area has been extended, but the net result is that the population from which longterm patients are drawn is only minimally smaller, at 333,447 in 1971 , and 325,480 in 1987.

\section{Findings}

In December 1973, 39 long-stay patients were identified by personal survey of each ward, i.e. an intake of about ten for each of the four years of intake 1967 to 1970. In 1987 the corresponding total was only 12 , an average of three per year from April 1980 to April 1984.

Figures for new long-stay male schizophrenic patients, i.e. over three years' stay, are not available for most of the years between the surveys, but in 1978 a count was made of such patients admitted in the years 1972 to 1975 inclusive, the number being 30 .

There has been a decrease in the number of male schizophrenic patients admitted. In 1967 to 1970 there was a total of 471 admissions (215 individuals), of whom 45 were first admissions, while the figures for April 1980 to April 1984 were 209 admissions (184 individuals), including 36 first admissions.

The 1973 cohort was not in fact assessed in detail until 1975, when the numbers had been reduced by six (three discharges, three deaths), so that the total available for comparison with the 1987 group is 33 . There was a comparable attrition of numbers in the two years following the 1987 census (see 'Subsequent changes').

\section{Age}

There was no appreciable difference in mean age, which was 45.4 in 1973, and 46 in 1987.

\section{Duration of illness}

In 1973 the average duration was 15 years, with a range from 5 to 40 years. In 1987 it was 20 years, ranging between 4 and 28 years.

\section{Number of previous admissions}

In 1973 the average was 3.3, and in 1987 it was 4.6. Three of the 1987 cases had been previously treated in the adjacent general hospital psychiatric unit.

\section{Marital status}

In 1973 seven men $(21.2 \%)$ had been married, although only three retained any contact with their wives. Only one of the 1987 group, however, had ever been married, and indeed re-married during his stay.

\section{Place of origin}

The 1973 cohort had contained only two immigrants. All the patients in the 1987 cohort originated in the Glasgow area and came from the indigenous population, none being immigrants. Five had their original address in the Leverndale catchment area, six from the area of the adjacent general hospital psychiatric unit, and one from outside both areas.

\section{Occupation in hospital}

In 1973 two patients held outside employment, and 15 worked within the hospital, 13 of these at the industrial therapy unit. Eleven were incapable of any regular occupation and the remaining five attended occupational therapy or did ward work.

In 1987 one patient had a job outside hospital, one worked in the Industrial Therapy Unit, one employed himself inefficiently in a hospital paper round, two attended occupational therapy, two did ward work, and the remaining five were incapable of any occupation.

\section{Special characteristics}

In 1973 five patients were noted to be aggressive, a further four both aggressive and suicidal. One elderly patient was in poor physical health.

In 1987 one patient showed recent serious aggression but no other special behavioural features were noted. Two patients had physical impairment, one having ankylosing spondylitis causing considerable disability, the other had bronchial carcinoma.

One patient had brain damage resulting from a suicide attempt, one was considered to have congenital brain disorder possibly due to birth injury. Four patients suffered from borderline or mild but definite mental subnormality, one of those having epilepsy as well.

\section{Subsequent changes}

Since the date of census in April 1987 there has been some reduction of numbers, four patients having been discharged and one, mentioned above, having died from bronchial carcinoma. The patient with ankylosing spondylitis was discharged to specialised sheltered accommodation, one was transferred to another mental hospital with his mental state unchanged, and two were discharged to relatives but are considered precariously placed there; one of these has married a female schizophrenic patient and they were discharged together. It appears, therefore, that a stay of over three years for male schizophrenic patients does not necessarily imply permanent residence in all cases.

\section{Comment}

The most striking finding is the drop in recruitment of new long-stay male schizophrenic patients from 39 in 1973 to 12 in 1987 , a reduction of $69 \%$. The fact that the new long-stay recruits had fallen to 30 in 1978 suggests that the reduction may be a trend rather than a chance variation. This has to be seen 
against the background of the figures for admissions of male schizophrenic patients, all of which have fallen but to varying degrees. Thus, all admissions and readmissions for male schizophrenic patients have fallen by $56 \%$, and first admissions by $20 \%$, but the number of individuals admitted has fallen only by $14 \%$. These surveys, therefore, appear to have marked a period of major change.

Demographic factors have to be considered. The new part of the catchment area consists of industrial towns which came within Greater Glasgow on the reorganisation of boundaries, with relatively little private housing and with pockets of high unemployment. Unemployment greatly increased in the region between the two surveys, being $5.2 \%$ in 1973 and $19.1 \%$ in 1987 (Strathclyde Regional Council, 1987). Such social factors seem unlikely to be reflected in reduced incidence or improved prognosis of schizophrenia. Examination of the catchment populations and their age distribution reveals only minor changes not statistically relevant in view of the age bands of the patients found (Bryden, 1989).

Changes in diagnostic practice seem unlikely to have played a significant part in these reductions, especially in the long-stay recruits, who all suffered from well-established chronic illnesses. Eagles, Hunter \& McCance (1988) considered this factor probably did not account for the fall in schizophrenic first-admissions and contacts observed in their own and other studies. A fall in the incidence of schizophrenia has to be considered in accounting for the results, but no definite conclusions can be drawn, since there were no data on total contacts for the 1967 to 1970 period, i.e. it is possible that more schizophrenic patients were treated in the community in 1981 to 1984 without ever being admitted to hospital.

The difference between the fall of total admissions $(56 \%)$ and the number of individuals admitted $(14 \%)$ shows that the revolving door is revolving more slowly, presumably in relation to the development of community facilities. There has been a reduction in the number of relapses leading to readmission, which might indicate less chronic disability, but it may be that minor relapses can now be dealt with more effectively in the community. Once admitted patients are also less likely to become long-stay residents. This is probably due to the increased emphasis on and facilities for rehabilitation, reflecting a change of expectations from those prevalent a generation ago, when long-term hospital care was the usual outcome anticipated for the type of patient considered here.

The nature of the patients becoming long-stay also appears to have changed, although the small numbers make conclusions tentative. Five of the 1987 patients had physical, including neurological, handicaps, and a further three borderline or mild mental subnormality without such handicaps, leav- ing only four $(33 \%)$ with uncomplicated schizophrenia, albeit in severe form and with incomplete response to treatment. Only one $\mathbf{( 8 . 3 \% )}$ was ever married, compared with $21.2 \%$ in 1973 . There has been a large drop in the number of in-patients capable of sustained work, as has been found, for example, by Ford et al (1987) who comment "if patients are capable of industrial training or sheltered work, then, with rare exceptions, they are living in the community".

The question arises as to whether the new longstay schizophrenic patients of 1987 can be cared for elsewhere than in a psychiatric hospital. There is a small group with severe and treatment-resistant psychoses who, in our opinion, can only be dealt with in aysychiatric setting for the foreseeable future; and it is mportant that this provision be retained. A greater number, however, have additional disabilities and merit further consideration. They require a degree of support and supervision which is, at present, not attainable outside the psychiatric hospital, and when assessed for or tried in other settings, have been found unsuitable or unable to cope. If supervised accommodation of some other kind were to become available, this might meet the needs of some of them; they could at least be said to be living in the community and might have a better quality of life than in a long-stay ward (Gibbons \& Butler, 1987). There is, at least in this particular hospital, some overlapping with the needs of the mentally subnormal, and this would need to be taken into account in devising suitable programmes of rehabilitation and after-care.

\section{Acknowledgement}

We wish to thank Dr A. V. M. Hughson for advice.

\section{References}

Bryden, J. (1989) Consultant in Health Information. Greater Glasgow Health Board (personal communication).

Eagles, J. M., Hunter, D. \& McCance, C. (1988) Decline in the diagnosis of schizophrenia among first contacts with psychiatric services in the North-East Scotland 1969-1984. British Journal of Psychiatry, 152, 793-798.

Ford, M., GodDARD, C. \& LAUSDALl-Welfare, R. (1987) The dismantling of the mental hospital? Glenside Hospital Surveys 1960-1985. British Journal of Psychiatry, 151, 479-485.

GibBons, J. S. \& Butler, J. P. (1987) Quality of life for 'new' long-stay patients; the effects of moving to a hostel. British Journal of Psychiatry, 151, 347-354.

StrathClyde Regional CounCIL (1987) Employment Statistics. Glasgow.

Todd, N. A., BenNie, E. H. \& CaRlisle, J. M. (1976) Some characteristics of 'new long-stay' male schizophrenics. British Journal of Psychiatry, 124, 424-427.

-(1974) Patterns of admissions in schizophrenia. British Journal of Psychiatry, 125, 558-592. 